\title{
Computerised infrared thermography and isotopic bone scanning in tennis elbow
}

\author{
Dale Thomas, ${ }^{*}$ Georgia Siahamis, Millicent Marion, Cathy Boyle
}

\begin{abstract}
Thirty five cases of tennis elbow ( 17 unilateral, nine bilateral) were studied with infrared thermography and isotopic bone scanning. A hot focus was visualised in 16 of 17 cases of unilateral tennis elbow (94\%) and in all nine cases of bilateral tennis elbow (100\%) on infrared thermography, and abnormal increased epicondylar activity seen in 12 of 17 (71\%) and eight of $18(44 \%)$ cases respectively with isotopic bone scanning. Unilateral visual cooling (somatosympathetic responses) occurred in seven of 13 cases of unilateral tennis elbow (54\%) with infrared thermography, and reduced perfusion in seven of 12 (58\%) of similar cases with blood pool isotopic bone scanning.

Computerised temperature assessments showed statistically significant side to side temperature differences when 17 active tennis elbows were compared with the opposite normal elbows for spot temperatures, proximal and distal forearm gradients. Similar temperature assessments in 18 bilateral tennis elbows compared with 17 normal elbows showed significant temperature differences for elbow spot temperatures and distal forearm gradients, but not for proximal gradients.
\end{abstract}

Tennis elbow is a common painful condition of the lateral elbow with localised epicondylar tenderness and a tendency to recur. The pathogenesis in most cases is now believed to involve a microtear at the origin of the extensor carpi radialis brevis accompanied by inflammatory granulation tissue. $^{1}$

Infrared thermography supports an inflammatory, vascular pathogenesis with a characteristic hot focus over the lateral epicondyle. ${ }^{23}$ In the study of Binder et al temperature gradient analysis across the abnormal lateral elbow area showed correlation with clinical severity. ${ }^{2}$ Nuclear medicine skeletal imaging is a sensitive technique for evaluating bone and muscle abnormalities, and in tennis elbow the late bone phase shows a focal 'hot area' at the 'enthesis', the site of tendon attachment to bone. ${ }^{4}$ Thomas and Savage reporting a case of persistent tennis elbow, in which thermography correlated with isotopic bone scanning, also suggested that lateral epicondyle temperature analysis, combined with forearm temperature gradient analysis, may be of more clinical value than isolated lateral temperature or side to side (symptomatic to asymptomatic) temperature analysis. ${ }^{3}$ Our study aimed at comparing infrared thermography with isotopic bone scanning (blood pool and bone phases) and defining parameters that may be of diagnostic value in tennis elbow.

\section{Patients and methods}

Thirty five cases of active tennis elbow (17 unilateral, nine bilateral) were defined by clinical examination in 26 patients ( 20 female, six male) with a mean age of 41 years (range 27-58). Localised lateral epicondyle point tenderness and pain on resisted wrist extension were required for clinical diagnosis. Before thermographic assessment a rigid standardised preassessment protocol was used that required the patient to refrain from eating or drinking for three hours before the test; taking any tablets on the day of the test; applying creams to the arms or hands; smoking for three hours before the test; performing any exercise or receiving hydrotherapy, physiotherapy, or acupuncture; covering the elbows with bandages, splints, braces on the day of the test; applying local friction to the elbow area; suntanning for seven days before the test.

Patients removed clothes to expose both arms and equilibrated in a relaxed air conditioned room at a room temperature of $21^{\circ} \mathrm{C}$ for 20 minutes before thermographic assessment. Thermal assessments were made with an Agema 782 system connected to an IBM PC, programmed with computer assisted thermographic software. Lateral views of both elbows were taken on 52 elbows, of which 35 had active epicondylitis and 17 were the opposite normal elbow. All thermograms were examined visually for a hot focus over the lateral elbow, as described by Binder et al. ${ }^{2}$ Also, a visual assessment for thermal asymmetry was made by comparing thermal patterns of symptomatic and asymptomatic forearm and hand regions in 13 patients with unilateral tennis elbow. This was to detect 'somatosympathetic reflexes'-that is, reflex sympathetic efferent responses secondary to painful nociceptor stimulation. The cutaneous thermal change reflecting the somatosympathetic reflex is invariably a cooling response. ${ }^{5}$

Three computer derived measurements were made: (a) the lateral elbow spot temperatures over the centre of the hot focus on the symptomatic side and mirror image region of the normal side; $(b)$ the proximal temperature gradient between the lateral epicondyle (hot focus) and the mid-extensor forearm spots; (c) the distal temperature gradient between the lateral epicondyle and the mid-extensor wrist temperature spots. All patients were bone scanned on the same or the next day with a GE 
$400 \mathrm{~T}$ or a Siemens orbiter gammacamera, connected to a digital PDP 11/34 computer, after injection of $900 \mathrm{mBq}$ of technetium-99m methylenediphosphonate. Analysis consisted of a visual assessment of abnormality in multiple views of the region of the humeral epicondyles in the late two hour bone scan and also the early two to five minute blood pool phase scans. Computer counting in the early and late phases was performed in 10 cases. Also, a visual assessment of the early blood pool scans was made in 12 cases of unilateral tennis elbow to obtain evidence of altered perfusion for the purpose of assessing somatosympathetic reflexes.

\section{Case reports}

A CASE OF UNILATERAL TENNIS ELBOW

A 39 year old female laboratory assistant developed an acute left tennis elbow in December 1988 after catching a falling tray of bottles. Epicondylar pain persisted despite physiotherapy, steroid injection, and work modifi-
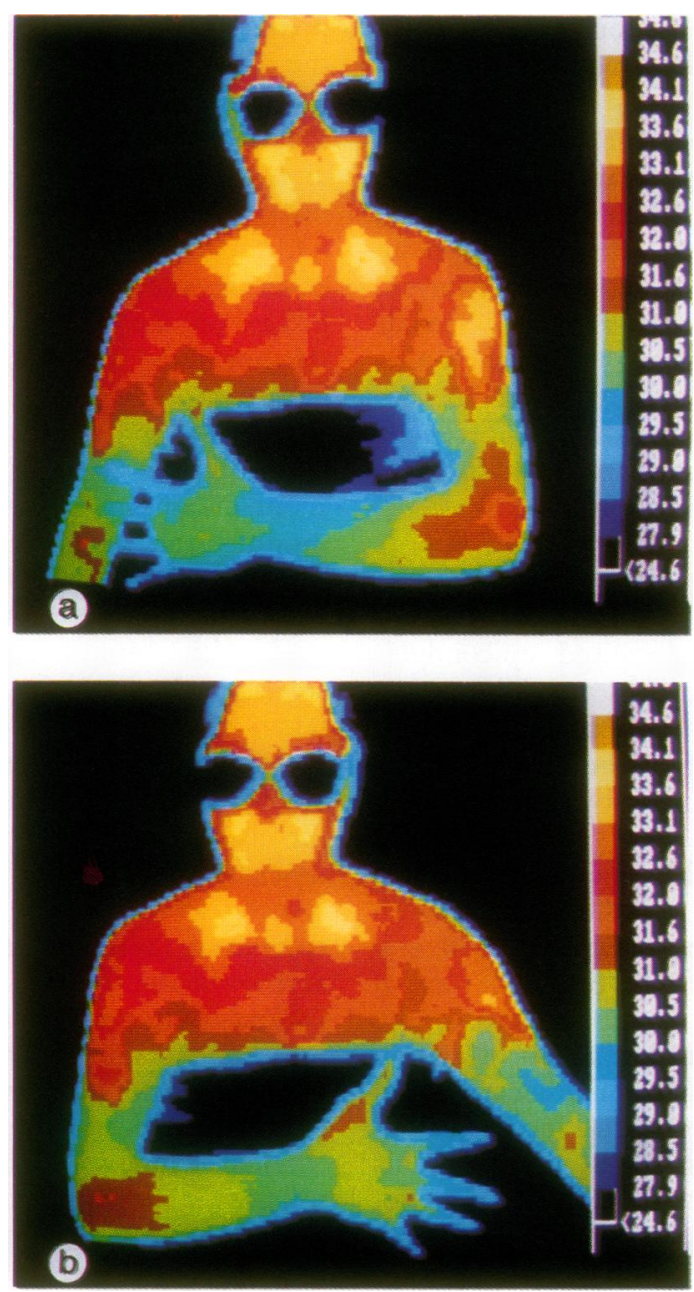

Figure 1 (a) Thermogram of the left lateral arm, Fune 1988 , with a hot focus at $32.5^{\circ} \mathrm{C}$ over the lateral epicondyle typical of active epicondylitis. The left elbow to mid-forearm temperature gradient was increased at $1.6^{\circ} \mathrm{C}$ (compared with $0.7^{\circ} \mathrm{C}$ for the asymptomatic right side). Cooling extends to the dorsal hand and fingers, indicating a somatosympathetic response. (b) Thermogram of the asymptomatic right lateral arm. Spot temperature of the right epicondyle is $31.6^{\circ} \mathrm{C}$ and the elbow to mid-forearm gradient is $0.7^{\circ} \mathrm{C}$. The increased heat in the extensor muscles distal to the epicondyle shows a more uniform normal distribution. cation. Examination in June 1988 showed localised grade 3 tenderness (withdrawal response), and $20^{\circ}$ fixed flexion deformity of the elbow. Infrared thermography and nuclear scanning confirmed an active left lateral epicondylitis with a hot focus over the lateral elbow and increased distal thermal gradients (cooling somatosympathetic response) on infrared thermography (figs 1a and b) and on nuclear scanning characteristic focal nuclide accumulation at the enthesis (fig 2a) and reduced forearm to hand perfusion on the blood pool phase (fig 2b).

Clinical improvement was present in September 1988 with reduced localised tenderness and full range of movement of the elbow. This was reflected thermographically with a lowering of spot temperature over the lateral epicondyle and lessening of the distal thermal gradient (fig 3).

\section{A CASE OF BILATERAL TENNIS ELBOW}

A 58 year old male plastics cutter developed bilateral elbow and forearm pain gradually worsening for 12 months before presentation. The right side was more painful. Examination showed point tenderness over both lateral epicondyles with positive stress testing of the right and negative stress testing of the left. Infrared imaging showed abnormalities over the lateral epicondyles, with the right hotter than the left (figs $4 a$ and $4 b$ ). Nuclide scanning (two hour bone phase) showed increased uptake in the lateral epicondyles, with the right greater than left (fig 5). Both infrared thermography and nuclide scanning demonstrated changes that confirmed the clinical diagnosis accurately.

\section{Results}

In the 17 patients with unilateral tennis elbow the mean elbow spot temperature was $31 \cdot 12$ (SD 0.88$)^{\circ} \mathrm{C}$, the mean proximal forearm gradient $1.14(0.64)^{\circ} \mathrm{C}$, and the mean distal forearm gradient $1.5(1 \cdot 19)^{\circ} \mathrm{C}$. The 17 opposite normal (control) elbows had a mean spot temperature of $30.5(0.85)^{\circ} \mathrm{C}$, a mean proximal forearm gradient of $0.59(0.74)^{\circ} \mathrm{C}$, and a mean distal forearm gradient of $0.66(0.96)^{\circ} \mathrm{C}$. The respective side to side differences (that is, abnormal to normal elbow) for spot temperature, proximal and distal forearm temperature gradients were significantly different at $p<0.001$, $\mathrm{p}<0.001, \mathrm{p}<0.001$ respectively (paired $t$ test) (table 1).

The mean elbow spot temperature in 18

Table 1 Lateral elbow spot temperatures, proximal and distal forearm temperature gradients for unilateral active tennis elbows and inactive opposite control elbows. Results are given as mean $(S D)$

\begin{tabular}{llll}
\hline & $\begin{array}{l}\text { Unilateral tennis } \\
\text { elbows }(n=17)\end{array}$ & $\begin{array}{l}\text { Control elbows } \\
(n=17)\end{array}$ & $p$ Value \\
\hline $\begin{array}{l}\text { Elbow spot } \\
\text { temperature }\left({ }^{\circ} \mathrm{C}\right)\end{array}$ & $31.12(0.88)$ & $30.5(0.85)$ & $<0.001$ \\
$\begin{array}{l}\text { Proximal forearm } \\
\text { gradier.t }\left({ }^{\circ} \mathrm{C}\right)\end{array}$ & $1.14(0.64)$ & $0.59(0.74)$ & $<0.001$ \\
$\begin{array}{l}\text { Distal forearm } \\
\text { gradient }\left({ }^{\circ} \mathrm{C}\right)\end{array}$ & $1.5(1.19)$ & $0.66(0.96)$ & $<0.001$ \\
\hline${ }^{*}$ Student's $t$ test (paired). & &
\end{tabular}


Table 2 Bilateral elbow spot temperatures, proximal and distal forearm temperature gradients for bilateral tennis elbows, compared with control elbows. Results are given as mean $(S D)$

\begin{tabular}{lccl}
\hline & $\begin{array}{c}\text { Bilateral tennis } \\
\text { elbows }(n=18)\end{array}$ & $\begin{array}{l}\text { Control elbows } \\
(n=17)\end{array}$ & $p$ Value \\
\hline $\begin{array}{l}\text { Elbow spot } \\
\text { temperature }\left({ }^{\circ} \mathrm{C}\right)\end{array}$ & $31.5(0.88)$ & $30.5(0.84)$ & $<0.01^{*}$ \\
$\begin{array}{l}\text { Proximal forearm } \\
\text { gradient }\left({ }^{\circ} \mathrm{C}\right)\end{array}$ & $0.86(0.37)$ & $0.59(0.74)$ & $\mathrm{NS}^{*}$ \\
$\begin{array}{l}\text { Distal forearm } \\
\text { gradient }\left({ }^{\circ} \mathrm{C}\right)\end{array}$ & $1.56(1.25)$ & $0.66(0.96)$ & $<0.05^{*}$ \\
\hline *
\end{tabular}
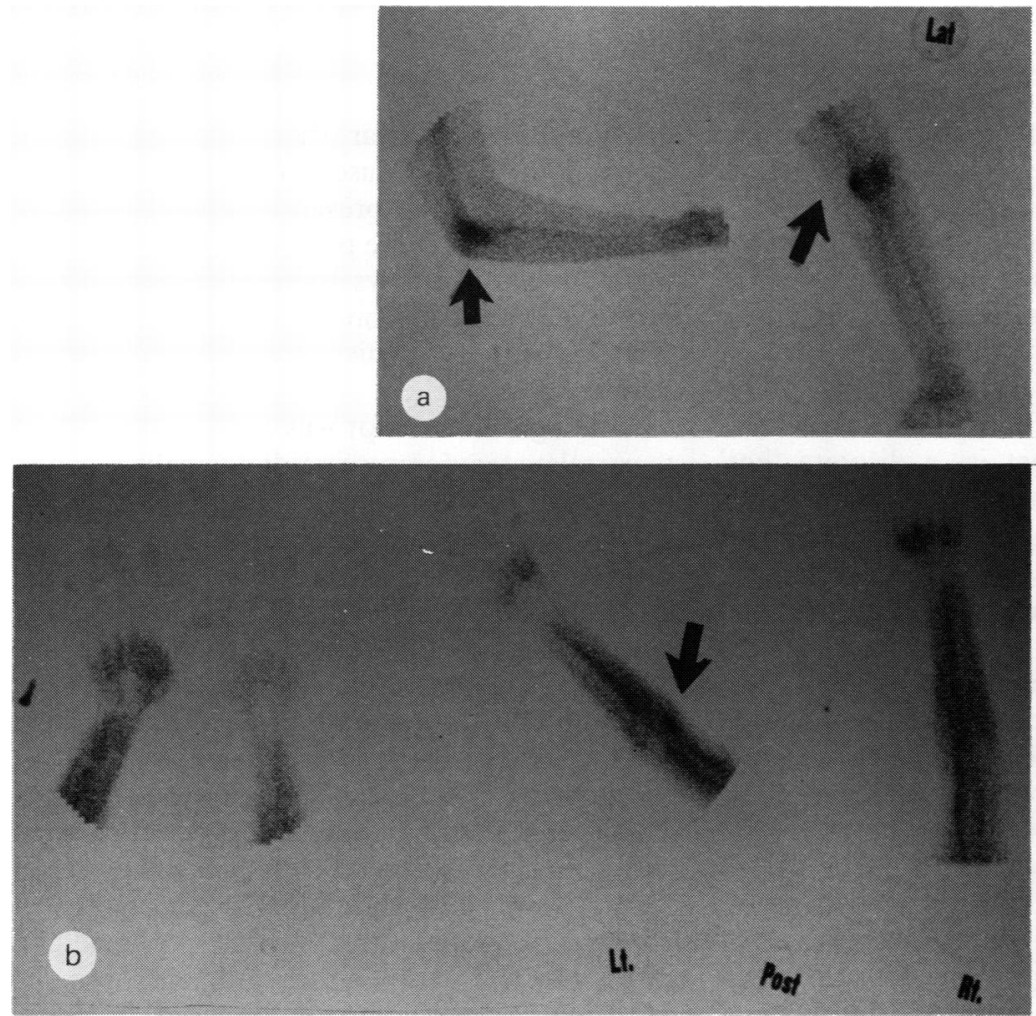

Figure 2 (a) Nuclide bone scan, May 1988, two and a half hours after injection of $900 \mathrm{mBq}$ of methylene diphosphonate labelled with technetium- $99 \mathrm{~m}$, showing marked focal nuclide accumulation at the 'enthesis' of the lateral epicondyle (arrowed). This is characteristic of lateral epicondylitis. (b) Early blood pool phase of scan $2 a$ (five minute phase), showing focal accumulation beginning over the enthesis (arrowed) and reduced perfusion to the left hand.

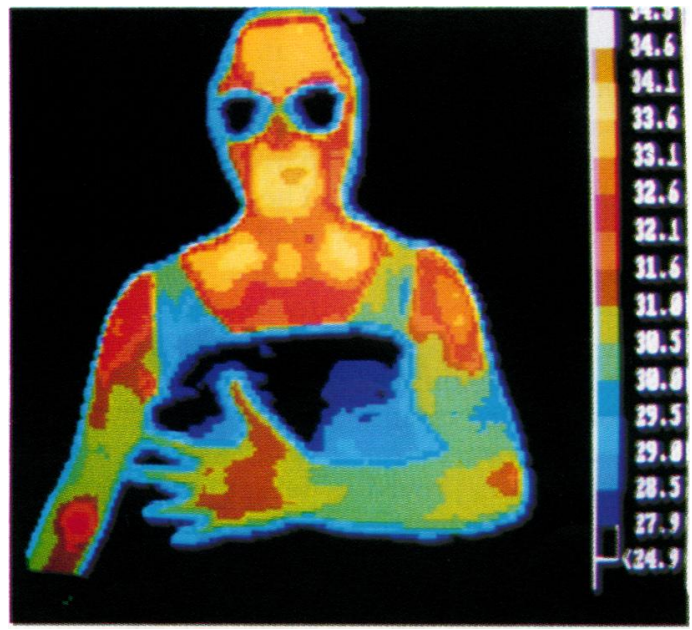

Figure 3 Thermogram of left tennis elbow, September 1988, demonstrating thermographic improvement. The left tennis elbow spot temperature is $31.6^{\circ} \mathrm{C}\left(0.9^{\circ} \mathrm{C}\right.$ cooler than in Fune 1988). The elbow to mid-forearm gradient has reduced $\left(1 \cdot 3^{\circ} \mathrm{C}\right)$ but remains abnormal compared with the contralateral normal side $\left(0 \cdot 4^{\circ} \mathrm{C}\right)$, indicating a persistent somatosympathetic reflex response secondary to residual epicondylar pain. bilateral tennis elbows was $31.5(0.88)^{\circ} \mathrm{C}$, the mean proximal forearm gradient $0.86(0.37)^{\circ} \mathrm{C}$, and the mean distal forearm gradient 1.56 $(1 \cdot 25)^{\circ} \mathrm{C}$ (table 2 ). A comparison of these results with the corresponding values for the 17 normal elbows showed significant side to side differences for elbow spot temperature $(p<0.01)$ and for
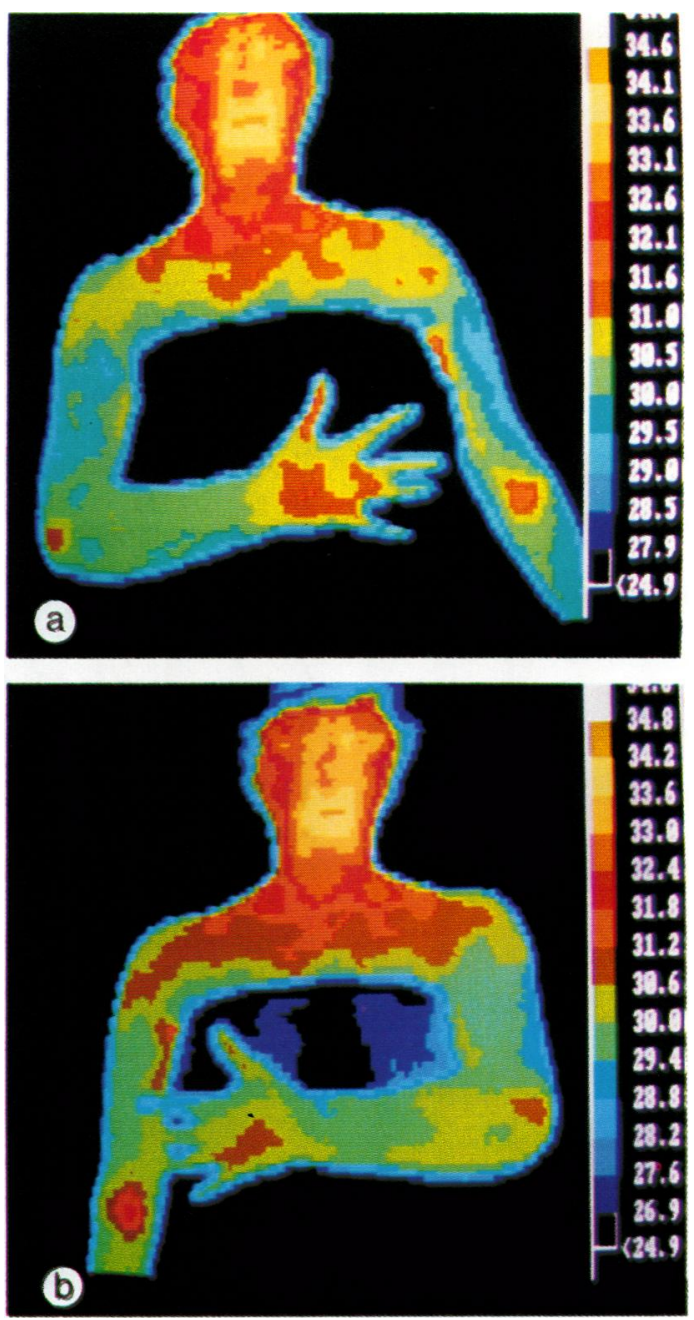

Figure 4 (a) Right lateral arm thermogram of a patient with pain in both elbows, with a hot focus at $31.4^{\circ} \mathrm{C}$ over the lateral epicondyle, indicating an active epicondylitis.

The elbow to mid-forearm temperature gradient is $0.6^{\circ} \mathrm{C}$ (normal). (b) Lefi lateral arm thermogram of the same patient as in $4 a$, with a hot focus at $31.0^{\circ} \mathrm{C}$ over the lateral epicondyle, indicating an active epicondylitis. The elbow to mid-forearm temperature gradient is $I^{\circ} 1^{\circ} \mathrm{C}$ (abnormal).



Figure 5 Nuclide bone scan (two hour phase) showing increased isotope uptake in the lateral epicondyles of both humeri. The right abnormality (right scan) is greater than the left side (left scan), consistent with bilateral tennis elbow (arrows highlight the lateral epicondyles). 
Table 3 Early and late phase isotopic bone scan elbow joint counts for ten unilateral tennis elbows

\begin{tabular}{|c|c|c|c|c|c|c|}
\hline Case No & $\begin{array}{l}\text { Active } \\
\text { elbow }\end{array}$ & Late & Early & $\begin{array}{l}\text { Control } \\
\text { elbow }\end{array}$ & Late & Early \\
\hline $\begin{array}{r}1 \\
2 \\
3 \\
6 \\
7 \\
14 \\
15 \\
16 \\
20 \\
21\end{array}$ & $\begin{array}{l}\text { L } \\
\mathbf{R} \\
\mathbf{R} \\
\mathbf{R} \\
\mathbf{R} \\
\mathbf{L} \\
\mathbf{L} \\
\mathbf{R} \\
\mathbf{R} \\
\mathbf{R}\end{array}$ & $\begin{array}{l}1.37 \\
2.07 \\
1.56 \\
1.5 \\
-1.21 \\
1.6 \\
1.5 \\
1.47 \\
1.35\end{array}$ & $\begin{array}{l}- \\
0.96 \\
1.0 \\
0.91 \\
0.7 \\
0.79 \\
1.44 \\
0.52 \\
0.78 \\
0.84\end{array}$ & $\begin{array}{l}\text { R } \\
\mathbf{L} \\
\mathbf{L} \\
\mathbf{L} \\
\mathbf{L} \\
\mathbf{R} \\
\mathbf{R} \\
\mathbf{L} \\
\mathrm{L} \\
\mathrm{L}\end{array}$ & $\begin{array}{l}1.26 \\
1.85 \\
1.39 \\
1.3 \\
-1.45 \\
1.38 \\
1.5 \\
1.55 \\
1.24\end{array}$ & $\begin{array}{l}- \\
0.78 \\
1.0 \\
0.91 \\
0.72 \\
0.85 \\
1.25 \\
0.82 \\
0.78 \\
0.80\end{array}$ \\
\hline $\begin{array}{l}\text { Mean } \\
\text { SD }\end{array}$ & & $\begin{array}{l}1.51^{*} \\
0.24\end{array}$ & $\begin{array}{l}0.88 \dagger \\
0.25\end{array}$ & & $\begin{array}{l}1 \cdot 44^{*} \\
0 \cdot 19\end{array}$ & $\begin{array}{l}0.88 \dagger \\
0.16\end{array}$ \\
\hline
\end{tabular}

${ }^{*}+\dot{N} S$ at $p<0.05$.

the distal forearm gradient $(p<0.05)$. There was no significant difference between the proximal forearm gradients.

Visual assessments of the lateral elbows showed increased heat over the lateral elbow in 16 of the 17 cases of unilateral tennis elbow ( $94 \%$ correlation) and in all nine cases (that is, 18 elbows) of bilateral tennis elbow (100\% correlation). The two hour bone scan was recorded as positive-that is, a discrete 'hot' focus was seen in 12 of the 17 cases of unilateral tennis elbow ( $71 \%$ correlation) and in eight of the 18 bilateral tennis elbows (44\% correlation). The early blood pool phase of the isotopic bone scanning did not show abnormalities in the region of the lateral epicondyle.

Although seven of the nine active unilateral tennis elbows had higher late phase isotopic counts than control elbows, the mean (SD) value of $1.51(0.24)$ was not statistically different from that of control elbows with a mean of 1.44 $(0 \cdot 19)$ (table 3). Early phase (blood pool) isotopic bone scan elbow counts in nine cases of unilateral tennis elbow gave an identical mean value of 0.88 compared with matched control elbows (table 3). Visual assessment of arm thermograms in 13 cases of unilateral tennis elbow showed significant peripheral regional cooling in seven (54\%) compared with the asymptomatic side. Thermal gradient analyses (elbow to mid-forearm and wrist) were abnormal with respect to the normal side in each of these seven cases. Regional perfusion was reduced in seven of $12(58 \%)$ of the same group with unilateral tennis elbow on early blood pool phase of the bone scan, indicating excellent correlation with thermography.

\section{Discussion}

In tennis elbow and other soft tissue conditions the objective assessment of severity and response to treatment is difficult to measure. Even the existence of the condition has proved difficult to confirm by standard diagnostic procedures.

This study shows that infrared thermography is a sensitive, objective, investigational procedure for the assessment of unilateral and bilateral tennis elbow. It provides the first reported confirmation, in a series of tennis elbows, of the original report of Binder et al $l^{2}$ published in 1983, in which patients with active unilateral tennis elbows were shown to have a discrete hot area near the lateral epicondyle (present in $98 \%$ of cases in that study and in $\mathbf{9 4 \%}$ of cases in the present study). Our study also shows that in nine patients (18 elbows) with bilateral tennis elbows there is increased heat over the lateral epicondylar areas in all cases ( $100 \%$ sensitivity). This has not previously been reported.

Although no attempt was made in this study to correlate temperature gradient analysis across the lateral elbow region with clinical severity, apart from the case reports described, many cases of tennis elbow that were assessed serially showed good correlation between the severity of epicondylar tenderness and thermographic changes. This was demonstrated by Binder $e t$ $a l,{ }^{2}$ who also showed that in normal arms there is a negative gradient across the elbow-that is, the elbow is colder than surrounding structures. Visual assessment of the thermogram is often sufficient to confirm the clinical diagnosis of tennis elbow, but computer based analysis of elbow spot temperatures and also proximal and distal forearm temperature gradients provide quantitative data that can be used to assess progress and response to treatments. The lateral elbow spot temperature in unilateral tennis elbow, and both proximal and distal forearm temperature gradients were all statistically of greater magnitude than values for the opposite normal arm.

In our experience as the tennis elbow responds to treatment and becomes clinically less active the lateral elbow spot temperature drops and narrows the side to side temperature difference. The proximal and distal forearm temperature gradients also reduce towards the opposite normal temperature gradients. The forearm temperature gradients, however, are slower to normalise than the lateral elbow temperature, and may remain abnormal when side to side lateral elbow temperatures are normal. This point was recently highlighted by Thomas and Savage, who suggest that analysis of absolute lateral epicondyle temperatures (that is, right to left differences) as well as gradient analysis provides more useful information than either parameter taken alone. ${ }^{3}$

The demonstration of abnormal forearm temperature gradients and significant unilateral cooling in $54 \%$ of cases of unilateral tennis elbow has not been previously reported. The lowering in dermal temperatures and reduced perfusion (on blood pool nuclide scan), in the 
same patients, probably represents a somatosympathetic reflex. The complex interrelation between the somatic and sympathetic nervous systems has been reported by Jinkins et $a l^{6}$ and studied in detail by Sato and Schmidt. ${ }^{7}$ Sato and Schmidt conclude that all somatic impulses produce sympathetic responses and, in particular, stimulation of small nociceptive pain fibres increases sympathetic nerve firings. The close association of pain and temperature decreases due to increased sympathetic vasoconstriction activity has been reported, ${ }^{89}$ and observed in many thermographic studies. ${ }^{10-13}$

Activation of localised (regional and segmental) sympathetic responses with concomitant clinical features of colour, temperature, sudomotor and sensory changes is poorly recognised by the clinician, but readily demonstrable by infrared thermography and the early flow and blood pool phases of the isotopic bone scanning. Sympathetic involvement also occurs in rheumatoid arthritis as shown by improvement in pain with sympathectomy ${ }^{14}$ and regional guanethidine infusion. ${ }^{15}$ Also, sympathetically maintained pain has been demonstrated in $40 \%$ of young adults with chronic anterior knee pain where unilateral lumbar sympathectomy relieves pain. ${ }^{16}$ Our experience that sympathetic blockade (regional guanethidine infusion) improves pain in a subgroup of patients with persistent tennis elbow, combined with the findings in this study that between 54 and $58 \%$ of patients with unilateral tennis elbow have sympathetic nerve abnormalities, suggests a rational basis for sympathetic blockade in chronic, persistently painful tennis elbow. The concept of sympathetically maintained pain has been discussed in detail by Roberts and Kramis. ${ }^{17}$

The inflammatory focus at the enthesis demonstrated by thermography and bone scan may be neurogenically modified as seems to be the case with inflammation in arthritis. ${ }^{18}$ It is likely that sympathetic mechanisms coparticipate in this 'neurogenic inflammation' and theoretically, therefore, treatments that modulate sympathetic activity (transcutaneous electrical nerve stimulation, ${ }^{19}$ acupuncture, ${ }^{20} 21 \quad \alpha$ adrenergic blockade) may not only reduce pain but also reduce enthesitic inflammation.

As far as we are aware the use of isotopic bone scanning in tennis elbow has not previously been reported in a formal study of patients with tennis elbow, though the reference to a 'hot focus' at the enthesis has been recognised and reported. ${ }^{4}$ Also, the use of bone scanning was not mentioned in a recent reappraisal of tennis elbow by Chard and Hazleman. ${ }^{22}$ In unilateral tennis elbow the two hour visual bone scan showed a higher correlation with infrared thermography than a similar correlation in bilateral tennis elbows $(77 \%$ and $44 \%$ respectively).

Bone scanning seems to be less sensitive than thermography in demonstrating changes at the lateral epicondyle in cases of both unilateral and bilateral tennis elbow. The poorer sensitivity in cases of bilateral tennis elbow may be due to less severe epicondylitis on one side or a difficulty in visually separating bilateral changes, which may produce a bias towards underreporting. Additionally, timing of the bone scan in relation to the original traumatic event may influence the positivity of the isotopic bone scanning as acute injury is more likely to be positive than chronic.

Measurements of isotopic uptake in unilateral tennis elbow in the early and late phases did not reach statistical significance when compared with the normal side, and seem not to add worthwhile information (although seven of the nine active elbows had higher counts than normal elbows). Difficulty with selection of the region of interest may be the chief cause of this finding.

1 Nirschl R P, Pettrone F A. Tennis elbow: the surgical treatment of internal epicondylitis. F Bone Foint Surg [Am] 1979; 61: 832-9.

2 Binder A, Parr G, Page Thomas P, Hazleman B. A clinical and thermographic study of lateral epicondylitis. $\mathrm{Br} \mathcal{F}$ Rheumatol 1983; 22: 77-81.

3 Thomas D, Savage J P. Persistent tennis elbow: evaluation by infrared thermography and nuclear medicine isotope scanning. Thermology 1989; 3: 132-6.

4 Matin P. Basic principles of nuclear medicine techniques for detection and evaluation of trauma and sports medicine injuries. Semin Nucl Med 1988; 18: 90-112.

5 Trattner $M$, Wolfe $R$ T F, Wursa R T, Hain T, Junkel W, Uematsu S. Somato sympathetic response to local trauma. Thermology 1987; 2: 595-6.

6 Jinkins J R, Whittemore A R, Bradley W G. The anatomical basis of vertebrogenic pain and the autonomic syndrome associated with lumbar disk extrusion. AfNR 1989; 10: 219-31.

7 Sato A, Schmidt R F. Somatosympathetic reflexes: afferent fibers, central pathways, discharge characteristics. Physiol Rev 1973; 53: 916-47.

8 Gandhavadi B, Rosen J S, Addison R G. Autonomic pain. Postgrad Med 1982; 71: 85-90.

9 Gross D. Pain and autonomic nervous system. Adv Neurol 1974; 4: 93-103.

10 Uematsu $S$. Thermographic imaging of cutaneous sensory segment in patients with peripheral nerve injury. f Neurosurg 1988; 62: 712-20.

11 Hubbard J E, Hoyt C. Pain evaluation in 805 studies by infrared imaging. Thermology 1986; 1: 161-6.

12 Thomas D, Cullum D, Siahamis G, Langlois S. Infra-red thermographic imaging, magnetic resonance imaging, $C-T$ scan and myelography in low back pain. Br $\mathcal{F}$ Rheumatol scan and myelography 1990 ; 29: 268-73.

13 Weinstein S A, Weinstein G. A review of 500 patients with low back complaints: comparison of five clinically accepted diagnostic modalities. Postgrad Med 1986; Spec No P40-3.

14 Levin J D, Fye K, Helter P, Basbaum A I, Whiting O'Keefe $O$. Clinical response to regional intravenous guanethidine in patients with rheumatoid arthritis. $\mathcal{F}$ Rheumatol 1986; 13: $1040-3$.

15 Herfort R A. Extended sympathectomy in the treatment of advanced rheumatoid arthritis. New York $\mathcal{F}$ Med 1956; 56: 1292.

16 Butler-Manuel P A, Justins D, Heatley F W. Sympathetically mediated pain in young adults with chronic anterior knee pain. Pain Suppl 1990; 5: Abs 812, S419.

17 Roberts J W, Kramis R C. Sympathetic nervous system influence on acute and chronic pain. In: Fields $\mathbf{H} \mathbf{L}$, ed. Pain syndromes in neurology. London: Butterworth, 1990: 85-106.

18 Kidd B L, Mapp P I, Blake D R, Gibson S J, Polak J M. Neurogenic influences in arthritis. Ann Rheum Dis 1990; 49: 649-52.

19 Owens S, Atkinson E R, Lees D E. Thermographic evidence of reduced sympathetic tone with transcutaneous nerve stimulation. Anesthesiology 1979; 50: 62-5.

20 Xiao-Ding C, Shao-Feng X, Wen-Xiao L. Inhibition of the sympathetic nervous system by acupuncture. Acupuncture and Electrotherapeutic Research International foumal 1983; 8: $25-35$.

21 Strauss S L. Scientific basis of acupuncture. Aust Fam Physician 1989; 16: 166-9.

22 Chard M D, Hazleman B L. Tennis elbow: a reappraisal. $B r$ I Rheumatol 1989; 28: 186-90. 